\title{
An Exploratory Examination of Interactions between Leadership Behavior and Person-Organization Value Fit on Employee Performance
}

\author{
A.G.K. Wijesinghe ${ }^{1}$ \\ Department of Agribusiness Management \\ Wayamba University of Sri Lanka \\ kusum_wijesinghe06@yahoo.com
}

\begin{abstract}
Many studies have shown that person-organization value fit effect on employee commitment, job satisfaction, involvement, communication, cooperation, and profit gains in organizations. Leader behavior is another important factor effects on employee performance in organizations. However research investigated on interaction effect of leader behavior and person-organization value fit on employee performance is mostly absent in literature. This study examined the effect of leader behavior, person-organization value fit and their interactions on employee commitment, participation for group decision making and trust in their leaders in Sri Lankan organizations. A questionnaire survey was undertaken to evaluate employees' ratings on these variables. Hypotheses testing were done by using Analysis of Covariates. Results revealed that both leader behavior and person-organization value fit are powerful predictors for employee performance. Theoretical and practical implications of these results and directions for future research are discussed.
\end{abstract}

Keywords: Leader Behavior, Person-Organization Value Fit, Employee Performance, Interaction Effect

\section{Introduction}

The differential role demand placed on leaders may vary according to demographic composition of organizations, organization culture, national culture, regional political systems, or the strategic requirements of the leader's in organizations (House, Hanges, Javidan, Dorfan, \& Gupta, 2004). Leader effectiveness has also been analyzed on the basis of the style adopted by the leader towards subordinates. Distinguishing between leaders adopting an autocratic, democratic or laissez-faire style of leadership and it had been concluded that democratic leadership was preferable from both productivity and behavioral

${ }^{1}$ http://orcid.org/0000-0002-0431-9823

Kelaniya Journal of Management | 2017 | Vol. 06 | Issue 02 | Page 15 
perspective (Hedges, 1995). Other situational leadership models suggest that leaders should change in their own behaviors in order to be truly effective. Among these are House's pathgoal model (House, 2007), Hersey and Blanchard's situational leadership model (Hersey \& Blanchard, 1977) and Vroom's decision making model (Vroom, 1974). The importance of taking into account the difference between people in different nations when studying management and leadership in any context is "because of management deals with the integration of people in a common venture and it is deeply embedded in culture (Hedges, 1995). Drucker (1988) has mentioned "what managers do is exactly the same but how they do it may be quite different" (cited by Hedges, 1995). Successful organizations today must have leaders or managers who motivate and inspire their employees. Many of the world's corporations today suffer from low employee morale and productivity, which lead to poorquality products and services, and higher costs. This is because of leaders in most corporations' lack of listening, feedback, and delegation skills needed to enhance employee commitment and improve productivity (Love, 2005). Profit margin of any company can be enhanced only by reduction of cost of production or service. A higher profit margin indicates a more profitable company that has better control over its costs compared to its competitors. Profit margin can be enhanced by committed work force successfully (Profit margin, www.investopedia.com). A major question addressed by House et al., (2004) is, in the extent to which specific leader characteristics and actions are universally endorsed as contributing to effective leadership, and the extent to which these qualities and actions are linked to cultural characteristics. They have identified six global leadership characters which are culturally endorsed such as, charismatic or value-based leadership, team-oriented leadership, participative leadership, human-oriented leadership, autonomous leadership and selfprotective leadership (House et al., 2004, p.42-48). According to the results of these former findings, researcher assumes that team-oriented behavior with additional characteristics of administrative competencies is the most suitable leadership behavior for Sri Lanka.

Person-organization value fit is another important issue in management. Even many authors have studied this issue in many years (Thomas, 2013; Hoffman, Bynum, Piccolo, \& Sutton, 2011; Sutarjo, 2011; Li, 2006; McCulloch \& Turban, 2007; Wijesinghe, 2007, 2008). Also past research has suggested that person-organization value fit affects job satisfaction, involvement, cooperation, communication, commitment of the employees and profit gain in companies (Thomas, 2013; Chatman, 1989, 1991; Chatman \& Barsade, 1995; Li, 2006; McCulloch \& Turban, 2007). Previous research also suggests that person-organization value 
fit is related to socialization and work outcomes (McCulloch \& Turban, 2007), positive effect on communication between leaders and their subordinates (assuming that leaders share the values of their organization) (Silverhart \& Hinchcliffe, 1996). Another scholar has mentioned that if managers really want to create a successful, productive workplace, the secret is simply to build trust, a sense of purpose and strong human relationships (Amble, 2007). The greater communication is likely to result in to greater understanding and trust between leader and his or her subordinates (Li, 2006; Meglino, Ravlin, \& Adkins, 1989).

Though person-organization value fit is so important phenomenon in organizational management, an organization has to keep those employees whose values do not fit its organizational culture, because of labor shortage or because of the need to remain creative and innovative human resources ( $\mathrm{Li}, 2006)$. However only few studies so far have been tested on interaction effect between leader behavior and person-organization value fit in relation to employees' performance. Li, (2006) has rightly mentioned that at least among Oriental Chinese firms, feminine leadership has significant effect on person-organization value fit, motivation, employees trust in their leaders and commitment. Also Li (2006) has mentioned that future research should further test the effectiveness of leader behavior in different cultures or societies. Present study extended previous research in changing culture and also by adding a new parameter to employee performance i.e. employee participation for group decision making. And also some methodological changes were included.

\section{Literature Review}

\section{Patterns of Leader Behavior in Different Cultures}

Dorfman (2004) has mentioned (cited by House et al., 2004) that leadership styles emphasizing participation, which are commonly accepted the individualistic West, are of questionable effectiveness in the collectivistic East. Literature says, Asian managers place heavy emphasis on paternalistic leadership and group maintenance activities. Charismatic or value-based leadership may display a highly assertive manner, as in the case of John F. Kennedy's or Martin Luther's leadership behaviors mentioned in the GLOBE study (House et al., 2004). A leader who "listens carefully to what you say" is seen as more rewarding in the U.S. than in China. The Malaysian leader is expected to behave in a manner that is humble, modest, and dignified. In India, there is a preference for leadership that is proactive, morally principled, ideological, bold, and assertive, in contrast to reactive, pragmatic, instrumental, quiet, and nurturing. By considering all those factors and cultural values of countries the 
GLOBE study has identified six global leadership characters; i.e. Charismatic/value based leadership, team-oriented leadership, participative leadership, human-oriented leadership, autonomous leadership, and self-protective leadership.

Leaders in countries where cultural norms are more tradition-bound often take factors other than merit in to account if deciding on salary increases. On the other hand, leaders from modern societies tend to focus more on issues of merit, orderliness, punctuality, intended rationality, and progress. Hence the differential role demand placed on leaders may vary according to demographic composition of organizations, national or regional political systems, or the strategic requirements of the organizations (House et al., 2004).

\section{Person-Organization Value Fit and Leader Behavior}

Person-organization value fit is the congruence of an individual's beliefs and values with the culture, norms, and values of an organization. An organization whose members are acculturated to behave morally according to specified principle practice that "the organizational good"; i.e. culture of the organization. "The organizational good" is the soul of an organization and as such, it shouldn't change. Verquer, Beehr, and Wagner (2003) have found that value dimensions of congruence in person-organization fit demonstrated stronger relationships to all three outcomes, job satisfaction, commitment and intent to turnover. A study conducted in Taiwan found that person-organization fit is a key element in both the level of job satisfaction that employees experience and also in their level of organizational commitment. Also this study has strongly mentioned that person-organization fit is an important variable within the organizations in non-western cultures (Silverthorn, 2004). Taris, Feij, and Vianen, (2005) have mentioned, good or optimal fit leads to positive work outcomes, while poor person-organization fit is usually associated with negative results. Li (2006) has mentioned that person-organization value fit has significant effect on employee performance in China.

Chatman (1991) has found that person-organization fit is influenced by selection and socialization. Normally recruits learn less about the norms and values of the firm through formal socialization practices and more about the technical aspects. Hence leader behaviors may contribute to greater person-organization fit by informally conveying to the recruits norms and values of the organization ( $\mathrm{Li}, 2006)$. Li (2006) has suggested that leader behavior can influence person-organization value fit. For example, Silverhart and Hinchcliffe (1996) observed that, with person-organization fit, management and employees are more likely to 
use the same language and have better communication than when there is no such fit. Meglino (1991) tested the relationship between value congruence and satisfaction with a leader. They found that congruence between an employee's values and the rated values of a leader was linked with the satisfaction with the leader. Past research seems to suggest that not all leader behaviors will influence person-organization value fit to the same extent. The leader behaviors that involve more intensive interaction between the leader and his or her subordinates may have greater impact on person-organization value fit by affecting the values, attitude and behaviors of subordinates ( $\mathrm{Li}, 2006$ ). Another research has shown that a significant effect between charismatic leadership and person organization value fit on employees' outcomes (Huang, Cheng, \& Chou, 2005). Li (2006) has mentioned, feminine leadership approach with its emphasis on interactive and team oriented is one of the most relevant leadership behavior for person-organization value fit in the Chinese cultural context.

\section{Influence of Sri Lankan Cultural Values on Leadership and Management}

Within the historical legacy of feudalism, Sri Lankan self-esteem is identified with family (Gamage, Cameron, \& Woods, 2003). Sri Lankans think in terms of collective and not individual values as society is not built on the individual but on the family. It comes naturally for Sri Lankans to put the focus on combined interest of the family. The Sri Lankan cultural orientation is supported by shared values which function as the basis of shared behavior. Further, compared to the west Sri Lankans prefer a more "structured" social order and therefore, Sri Lankans are less autonomous and more dependent on their place in the surrounding social system. Society in Sri Lanka always expects social responsibility and sharing attitude, rather than favoring quick achievement of higher expectations by individuals. The results are less assertive orientation to personal achievement in the wider social context in Sri Lanka (Gamage et al., 2003). House and his team in the GLOBE project have studied societal cultures and organizational cultures under 10 clusters in 62 countries. They found that Asian managers place a heavy emphasis on paternalistic leadership and group maintenance activities. In the GLOBE project they have empirically proved that effectiveness of leader behavior is culturally contingent (House et al., 2004).

\section{Conceptual Model and Development of Hypotheses}

Based on the literature survey and objectives of the study, hypotheses were developed as follows. Considering of culturally endorsed implicit theory of leadership in the GLOBE project study and Sri Lankan cultural values, researcher predicted that the "team-oriented 
DOI: http://doi.org/10.4038/kjm.v6i2.7543

leader behavior with administrative competencies" can enhance person-organization value fit and employee performance and hence it is considered as independent variable for the study.

\section{Leader Behavior and Person-Organization Value Fit}

Based on past research on leadership, organizational culture and person-organization value fit, the researcher argues that leader behavior can influence person-organization value fit. Sri Lankans think in terms of collective and not on individual values as society is not built on the individual but on the family. The Sri Lankan cultural orientation is supported by shared values which function as the basis of shared behavior (Gamage et al., 2003). If leader adopts a team-oriented leader behavior with administrative competencies, leader has more opportunity to influence his or her subordinates effectively. Greater affection and communication may enhance the socialization of employees resulting in higher personorganization value fit. When organization members have sense on each other and work as a group for organizational overall objective, they have more opportunities in influencing each other in adapting to the culture of the organization and thus, improving the personorganization value fit ( $\mathrm{Li}, 2006)$. Based on these concepts, following hypotheses were developed:

Hypothesis 1.a: Team-oriented leader behavior will have positive correlation with person-organization value fit.

Hypothesis 1.b: Team-oriented leader behavior will have positive correlation with employee commitment, participation for group decision making, and trust on their leaders.

\section{Leader Behavior on Employee Performance}

The primary concern of leaders with considerate and employee-centered style is the employee's welfare (Hersey \& Blanchard, 1977). The primary concern of leaders with initiating-structure and production-centered styles are achieving goals. However, employee oriented leaders appear to be associated with high group productivity and job satisfaction (Hersey \& Blanchard, 1977, Wijesinghe, 2009). Fiedler (1967) demonstrated that employee performance and satisfaction are positively influenced when the leader compensates for the shortcomings in either the employee or the work setting. Asian managers place heavy emphasis on paternalistic leadership and group maintenance activities. Path-Goal theory assumes that leaders are flexible and that they can change their style, as situations require. 
Effective leaders clarify the path to help their followers achieve their goals and make the journey easier by reducing roadblocks and pitfalls. Hence researcher proposes if leader is team-oriented, he or she can improve communication, empathy, participation, and involvement of subordinates. Based on these, following hypothesis was developed,

Hypothesis 2: Team-oriented leader behavior will significantly effect on employee commitment, participation for group decision making, and trust in their leaders

\section{Person-Organization Value Fit and Employee Performance}

If person-organization value fit is high, first employees who hold similar values should share common aspects of cognitive processing that should lead to common method of interpreting events. Common interpretation reduce uncertainty and stimulus overload and improve interpersonal relationships presumably, in part, by reducing conflict and misunderstanding (Li, 2006). Also employees will be satisfied with agent in the work situation, if agents perceive that as having important values in common with him or her (Kalliath, Bluedorn, \& Strube, 1999). Hence researcher proposed:

Hypothesis 3: Person-organization value fit will significantly effect on employee commitment, participation for group decision making, and trust in their leaders.

\section{Interactive Effect of Leader Behavior and Person-Organization Value Fit}

Also past research has suggested that person-organization value fit effects on job satisfaction, involvement, cooperation, communication and commitment of the employees (Tomas, 2013; Li, 2006; McCulloch \& Turban, 2007). Many scholars argue that leader behavior effects on employees' motivation and commitment (Li, 2006; Huang et al., 2005). As both factors effect on employee performance there should be an interaction effect between these two factors. Hence researcher proposed that:

Hypothesis 4: There is an interaction between team-oriented leader behavior and personorganization value fit on employees' commitment, participation for group decision making and trust in their leaders

\section{Employee Behavior under Low Person-Organization Value Fit}

Though person-organization value fit is so important phenomenon in organizational management, an organization has to keep those employees whose values do not fit its 
organizational culture, because of labor shortage or because of the need to remain creative and innovative human resources $(\mathrm{Li}, 2006)$. Feminine Manager can improve the commitment and motivation of employees by adopting an appropriate leader behavior under Chinese cultural context ( $\mathrm{Li}, 2006)$. It is worthwhile to find whether this is true for other cultures even under different behavioral model of leadership. Hence researcher proposed:

Hypothesis 5: Team-oriented leader behavior will influence subordinates even under low person-organization value fit to improve employee commitment, participation in group decision making, and trust in their leaders.

\section{Methods}

The researcher adopted a questionnaire survey methodology for data collection. The reasons for using the questionnaire methodology were, to keep face confidentiality, to build credibility and to save official time of participants for the survey. Questionnaires were distributed among 250 employees in six organizations in the plantation sector in Sri Lanka. Organizations were selected purposively and participants were selected randomly. Respondents were middle managers, junior managers, and management assistants. 202 complete questionnaires were subjected to analysis.

\section{Measures}

Team-oriented leader behavior was measured by six items. First 3 items were adapted by GLOBE project (House et al., 2004) and Li (2006) study. Last 3 items were self-constructed through literature. The scale included questions that "there is a team spirit around here, people at my level work well together, people with whom I work function very effectively as a team, everything orderly in my organization, our leaders are administratively competent, and everything well organized". The scale showed satisfactory reliability (Cronbach's alpha ranging from $0.90-0.91$ ).

The items for measuring employee commitment, and trust in their leaders also were adapted from GLOBE project study and Li (2006) study. Items for measuring employee participation in group decision making were self-constructed. Items of measuring employee commitment were "I feel committed to the mission and direction of my organization; I expect to be with this organization for at least three more years, I feel hopeful about the future of my organization, and I like to perform above and beyond the call of my duty". The scale showed satisfactory reliability (Cronbach's alpha ranging from 0.82-0.85). Items of measuring 
employee participation for group decision making were "I have opportunities to present my views in organizational decision making process, my superior makes me encourage presenting my experience and decisions on existing problems, my superior listens to my opinion without any criticism, and I can express my opinion to my superior without any hesitation. The scale showed satisfactory reliability (Cronbach's alpha ranging 0.89-0.90). Items for measuring employee trust in their leaders were "All things considered, I have confidence in the top management of my organization, I have confidence in the leaders of my organization, and I can open my views to my leaders as they keep confidentiality. The scale showed satisfactory reliability in Cronbach's alpha ranging 0.74 - .85 (Li, 2006). All questions were rated in 7 point Likert scale.

Questions under person-organization value fit, asked employees about the extent to which they feel their values and organizational values are fit together. There were 19 pairs of items (38 questions) selected from an instrument developed by House and his team in GLOBE project (House et al., 2004). Person-organization value fit was measured using the seven categories of measurements. They were "performance orientation, future orientation, gender egalitarianism, individualism and collectivism, power distance, human orientation, and uncertainty avoidance". All items requested respondents to answer in both "As is" and "Should be" sentences. In "As Is" scale asked, respondents to indicate how descriptive each statement is regarding their current organizational environment and "Should Be" scale asked, respondents to indicate how well each statement describes them personally. The discrepancy between the scores from these two sentences reflected the level of person-organization value fit. The smaller the score, the higher the fit. Respondents rated the all items on a 7-point reversed scale other than gender egalitarianism. A higher score indicated lower agreement and lower score indicated higher agreement in each scale. But the scales of gender egalitarianism were vice versa. The scale showed satisfactory reliability (Cronbach's alpha ranging 0.83 - 0.98) (House et al., 2004).

\section{Control variables}

Past research has suggested that demographic attributes may moderate the effect of leader behavior and person-organization value fit (Chatman, 1991; Li, 2006). As a result age, gender, work experience of the current job and total work experience were considered as control variables. The values of these variables didn't show any equal distribution with other 
DOI: http://doi.org/10.4038/kjm.v6i2.7543

variables. To minimize the effect of these factors on other variables, these were considered as covariates.

\section{Findings and discussion}

Descriptive statistics are in the Table 1, explained the correlation coefficient between teamoriented leader behavior and employee commitment, participation for group decision making and trust in their leaders. They were positively significant.

Table 1: Descriptive Statistics

\begin{tabular}{|c|c|c|c|c|c|c|c|c|c|c|c|}
\hline No & Variables & Mean & $\mathrm{SD}$ & 1.1 & 2.1 & 2.2 & 2.3 & 2.4 & 3.1 & 3.2 & 3.3 \\
\hline 1 & $\begin{array}{l}\text { Independent } \\
\text { variable }\end{array}$ & & & & & & & & & & \\
\hline 1.1 & $\begin{array}{l}\text { Team } \\
\text { oriented } \\
\text { leader } \\
\text { behavior }\end{array}$ & 5.57 & 1.09 & 1 & & & & & & & \\
\hline 2 & $\begin{array}{l}\text { Dependent } \\
\text { variables }\end{array}$ & & & & & & & & & & \\
\hline 2.1 & $\mathrm{P}$-o value fit & 3.02 & .94 & $-.52 * *$ & 1 & & & & & & \\
\hline 2.2 & Commitment & 5.25 & .94 & $.75^{* *}$ & $-.64 * *$ & 1 & & & & & \\
\hline 2.3 & Participation & 4.84 & 1.1 & $.73 * *$ & $-.65 * *$ & $.83 * *$ & 1 & & & & \\
\hline 2.4 & $\begin{array}{l}\text { Trust in } \\
\text { leaders }\end{array}$ & 5.44 & .91 & $.82 * *$ & $-.47 * *$ & $.61 * *$ & $.57 * *$ & 1 & & & \\
\hline 3 & $\begin{array}{l}\text { Control } \\
\text { variables }\end{array}$ & & & & & & & & & & \\
\hline 3.1 & Sex & 1.4 & .38 & -.005 & -.11 & .01 & .04 & -.04 & 1 & & \\
\hline 3.2 & Age & 41 & 6.4 & -1.46 & $.28 * *$ & $-.21 * *$ & $-.20 * *$ & -.12 & -.06 & 1 & \\
\hline 3.3 & $\begin{array}{l}\text { Company } \\
\text { tenure }\end{array}$ & 10 & 4.3 & -.002 & $.17^{*}$ & -.11 & -.12 & .04 & -.03 & $.79 * *$ & 1 \\
\hline 3.4 & $\begin{array}{l}\text { Total } \\
\text { experience }\end{array}$ & 13.1 & 5.6 & -.038 & $.19 * *$ & -.10 & -.12 & .02 & .002 & $.73 * *$ & $.85 * *$ \\
\hline
\end{tabular}

Correlation is significant at $* \mathrm{p}<.05, * * \mathrm{p}<.01, * * * \mathrm{p}<.001$ (2-tailed), $\mathrm{N}=202$

Source: Survey Data

Correlation coefficient between team-oriented leader behavior and person-organization value fit was negatively significant $(\mathrm{r}=-.52, \mathrm{p}<0.01$ in 2-tailed). But the scale testing personorganization value fit was actually the difference between personal values and the perceived 
organizational values. The smaller the number, the higher the level of person-organization value fit. Therefore, negative correlation showed positive effects of the leader behavior on person-organization value fit. According to these findings, hypotheses H1.a and H1.b can be supported.

To test other hypotheses, Analysis of Covariates (ANCOVA) was used. ANCOVA can increase the precision of categorical data analysis). Effect of team-oriented leader behavior and person-organization value fit were tested with relation to their employees commitment, participation for group decision making and trust in their leaders. The last column ( $\mathrm{p}$ value) in Table 2 presents the values of 0.0008 and 0.0001 corresponding to Person-Organization value fit (PO fit) and team-oriented leader behavior. These values are lower than the 0.001 probability and hence it can be concluded that main effect of PO fit and team-oriented leader behavior are significant on commitment.

Table 2: Dependent Variable = Employee Commitment

Commitment $=\mathbf{T L}+\mathrm{PO}+\mathrm{PO} * \mathrm{TL}+\mathrm{Sex}+$ Age $+\mathrm{Com}$. Tenure + Total Ex.

\begin{tabular}{lcl}
\hline Variable & F value & P value \\
\hline Team-oriented leader & 84.08 & $<.0001^{* * *}$ \\
Person-organization value fit & 11.57 & $.0008^{* * *}$ \\
TL*PO fit & 14.81 & $.0002 * * *$ \\
Sex & 0.07 & 0.79 \\
Age & 1.38 & 0.24 \\
Company tenure & 1.9 & 0.17 \\
Total work experience & 0.24 & 0.62 \\
& \\
Notes: $* \mathrm{p}<.05, * * \mathrm{p}<.01, * * * \mathrm{p}<.001, \mathrm{PO} * \mathrm{TL}=$ Interaction \\
\multicolumn{2}{r}{ Source: Survey Data Analysis } \\
\end{tabular}

In Table 3, the last column shows (P value) values of 0.0008 and 0.0001 corresponding to PO fit and team-oriented leader behavior factors and both are less than 0.001 probability. Hence the main effects of PO fit and team-oriented leader behavior are highly significant on employee participation for group decision making. 
Table 3: Dependent Variable = Employee Participation

Participation $=$ TL + PO + PO $*$ TL + Sex + Age + Co. Tenure + Total Ex .

\begin{tabular}{lcc}
\hline Variable & F value & P value \\
\hline Team-oriented leader & 89.96 & $<.0001^{* * *}$ \\
Person-organization value fit & 11.64 & $.0008^{* * *}$ \\
TL*PO fit & 19.23 & $<.0001^{* * *}$ \\
Sex & 0.28 & 0.5977 \\
Age & 0.46 & 0.4986 \\
Company tenure & 0.25 & 0.62 \\
Total work experience & 0.92 & 0.3379 \\
\hline
\end{tabular}

Notes: $* \mathrm{p}<.05, * * \mathrm{p}<.01, * * * \mathrm{p}<.001$

Source: Survey Data Analysis

The last column ( $\mathrm{p}$ value) in Table 4 shows the values of 0.0018 and 0.0001 corresponding to PO fit and team-oriented leader behavior factors. Both of these values are significant in 0.001 probability. Hence the main effect of human-oriented leader behavior is highly significant even on employee trust in their leaders.

Table 4: Dependent Variable $=$ Employee Trust in Their Leaders

Trust in Leaders $=$ PO+TL + PO $*$ TL + Sex + Age + Com. Tenure + Total Ex .

\begin{tabular}{lcc}
\hline Variable & F value & P value \\
\hline & & \\
Team-oriented leader & 171.1 & $<.0001^{* * *}$ \\
Person-organization value fit & 10.02 & $.0018^{* * *}$ \\
TL*PO fit & 1.12 & 0.29 \\
Sex & 0.22 & 0.64 \\
Age & 3.05 & 0.08 \\
Company tenure & 1.63 & 0.20 \\
Total work experience & 0.53 & 0.47 \\
\hline
\end{tabular}

Notes: $* \mathrm{p}<.05, * * \mathrm{p}<.01, * * * \mathrm{p}<.001$

Source: Survey Data Analysis

Also findings of Table 2, 3 and 4 support the hypotheses $\mathrm{H} 2$ and H3. Two way interactions between team-oriented leader behavior and person-organization value fit on employee commitment and participation for group decision making is highly significant. But two-way interaction is not significant on employee trust in leaders at 0.05 probability. This provides the answer for the hypothesis H4 partially. 
Table 5, shows the results for employee commitment, participation for group decision making and trust in their leaders under different levels of leader behaviors and person-organization value fit. It provides the answer to hypothesis H5. First, researcher divided the data of teamoriented leader behavior in to two parts based on the mid-point of the rank as "high" and "low" groups. As well as, data of person-organization value fit also divided in to two parts as "high fit" and "low fit". Under the LSMEANS command, SAS program has provided a special set of means under each level of the factors called Least Squares Means as in Table 5. These means were compared by Least Significant Different Test in order to compare their significance at alpha 0.05 .

Table 5: Least Squares Means for Mean Separation

\begin{tabular}{|c|c|c|c|c|}
\hline $\begin{array}{c}\text { Person- } \\
\text { organization } \\
\text { value fit }\end{array}$ & $\begin{array}{c}\text { Team } \\
\text { oriented } \\
\text { leader }\end{array}$ & $\begin{array}{c}\text { Employee } \\
\text { commitment } \\
\text { (LS Mean) }\end{array}$ & $\begin{array}{c}\text { Employee } \\
\text { participation } \\
\text { (LS Mean) }\end{array}$ & $\begin{array}{c}\text { Employee trust in } \\
\text { their leaders } \\
\text { (LS Mean) }\end{array}$ \\
\hline 1 (High) & 1 (Low) & 3.86 & 3.2 & 3.9 \\
\hline 1 (High) & 2 (High) & 5.80 & 5.5 & 5.8 \\
\hline & & 4.7 & 4.2 & 5.3 \\
\hline 2 (Low) & 2 (High) & \multicolumn{4}{|c|}{ Source: Survey Data Analysis } \\
\hline \multicolumn{5}{r}{}
\end{tabular}

According to these results highest mean values for the employee commitment and participation for group decision making are shown by the combination of high team oriented leader behavior and high person-organization value fit. The second highest value shows by the combination of high team oriented leader behavior and low person organization value fit. If team oriented leader behavior is low, the mean value of employee commitment is low even under high person-organization value fit. According to these result researcher can elaborate that employees who are working under high team oriented leader behavior shows highest value of commitment and participation for group decision making. Further it can be concluded that the most important factor for commitment and participation for group decision making is the style of leadership. Interactive effect between leader behavior and personorganization value fit in employee trust in leaders was not significant in 0.05 probability. But it has an effect on employee trust in their leaders in 0.09 probability. If team-oriented leader behavior is high, the mean value of employee trust in leaders is high even under low personorganization value fit. 
Demographic variable such as age, sex, company tenure and total work experience did not show any significant effect on employee commitment, participation for group decision making and trust in their leaders other than moderate effect of age on employee trust in their leaders. Effects of these unevenly distributed demographic factors were treated by covariate analysis.

\section{Conclusion}

According to the findings of this study, team-oriented leader behavior with administrative competencies can enhance the employee commitment, participation for group decision making, and trust in their leaders in Sri Lankan cultural context. Team oriented leader behavior shows higher significant effect on employee performance in these three factors. Therefore leaders or managers can enhance their labor productivity through higher employee performance by adapting necessary leadership behaviors. An interaction effect between leader behavior and person-organization value fit was highly significant on employee commitment and participation for group decision making. It provides a clue that leader behavior and person-organization value fit make some influence on each other in deciding employee commitment and participation. Therefore managers or leaders can take this in to account in recruitment, selection and managing their workforce. When there is an interaction effect between these factors the main effect can be suppressed in some way. As a result both leader behavior and person-organization value fit are critical factors in human resource management in organizations. But employee trust in their leaders mainly depends on style adapted by the leader. Further this study has shown that, even under low person-organization value fit, team-oriented leader behavior with administrative competencies can enhance the level of employee performance. Results reveal that, people who are working under high team-oriented leader behaviors show higher performance in commitment, and participation for group decision making, even under low person-organization value fit.

Finally researcher can conclude that both leader behavior and person-organization value fit are powerful predictor for employee performance. But leader behavior is the most powerful predictor on employee performance. As well as organizations can be managed effectively even with those employees who have low person-organization value fit by moderating the style of leadership. 
DOI: http://doi.org/10.4038/kjm.v6i2.7543

\section{Limitations and Directions for Future Research}

Future research should further test the effect of leader behavior, person-organization value fit and their interactions in different sectors in Sri Lanka and as well as in relation to different cultures in the global context. Even under Sri Lankan cultural context further research should be conducted to test the effect of other leadership behaviors such as the charismatic, democratic and autocratic on employee task fulfilments and organizational productivity.

\section{References}

Amble, B. (2007). The key to commitment, Filed under: Engagement \& Motivation. www.management-issues.com/build. Online

Chatman, J. (1989). Improving Interactional Organizational Research: A model of personorganization fit. Academy of management review, 14, No. 3, p. 333-349.

Chatman, J. A. (1991). Matching People and Organizations - Selection and Socialization in public accounting firms, Administrative science Quarterly 36: 459

Chatman, J. \& Barsade, S.G. (1995). Personality, Organizational culture, and cooperation: Evidence from a business simulation, 423/Administrative science quarterly, 40,423-443

Fiedler, F.E. (1967). A theory of leadership effectiveness, New York: Willy, [online].

Gamage, H.R., Cameron, D., \& Woods, E. (2003). Are Sri Lankans Entrepreneurs Motivated by the Need for Achievement. $9^{\text {th }}$ international conference on Sri Lanka Studies, No 099, Matara, Sri Lanka, (online)

Hersey, P. \& Blanchard, K.H. (1977). Management of organizational behavior: Utilizing human resource. $3^{\text {rd }}$ ed. Englewood Cliffs, Prentice Hall, Inc.

Hedges, P.M. (1995). Leadership and culture: International perception of organizational leadership. Master's Thesis, School of Management and Marketing, Curtin University of Technology, Perth, 1995, CRICOS Provider Code 02637B. 
DOI: http://doi.org/10.4038/kjm.v6i2.7543

Hoffman, B.J., Bynum, B.H., Piccolo, R.F., \& Sutton. (2011). Person-organization value congruence: How transformational leaders influence work group effectiveness: Academy of management Journal, Volume 54, No. 4, 779-796

House, R. J., Hanges, P.J., Javidan, M., Dorfan, P.W. \& Gupta, V. (2004). Culture Leadership and Organizations, The GLOBE study of 62 Societies, USA, SAGE Publication, Pgs 918, ISBN 0-7619-2401-9

House, R.J. (2007). Path-goal theory of leader effectiveness. Administrative Science Quarterly, 1971, 16, 321-339, http:www.clemson.edu/saerc-2007/papers/i-2.pdf (accessed on 28 July 2008).

Huang, M.P., Cheng, B.S., \& Chou, L.F. (2005). Fitting in organizational values, The mediating role of person-organization fit between CEO charismatic leadership and employee outcome, International Journal of Man Power., Vol. 26, No.1.p. 35-625.

Kalliath, Bluedorn, \& Strube, (1999). A test of value congruence effect, Journal of organizational behavior, Vol.20, 1175-1198.

Li, J. (2006). 'The interactions between person-organization fit and leadership styles in Asian firms, an empirical testing'. International journal of Human Resource Management: 17:10 October, 1689-1706, ISSN 0958-5192.

Love, J. (2005). How to enhance employee commitment and improve productivity, ezine articles, http://ezinearticles (accessed on 25 July 2008).

McCulloch, M. C. \& Turban, D. B. (2007). Using person-organization value fit to select employees for high-turnover jobs, International Journal of Selection and Assessment, LIMRA International, USA, Vol. 15, no. 1

Meglino, B.M., Ravlin, E.C. \& Adkins, C.L. (1989). A work values approach to corporate culture: A field test of the value congruence process and its relationship to individual outcomes. Journal of Applied Psychology, 74, 424-432

Meglino, B.M. (1991). Value congruence and satisfaction with a leader-An examination of the role of interaction. Human Relations. Vol. 44, p. 481. 
DOI: http://doi.org/10.4038/kjm.v6i2.7543

Profit margin, Investopedia. www.investopedia.com/terms/p/profitmargin.asp (online 2016). Silverheart, T.A., \& Hinchcliffe, R.H. (1996). New selection tool assesses candidate/agency fit. LIMRA's Market facts, Hartford, vol. 15, no.3.p.4.

Silverthorn, C. (2004). The impact of organizational culture and person-organization fit on organizational commitment and job satisfaction in Taiwan, Journal of leadership and organizational development, Vol.25, no.7, p.592-599, (online), http://www.emeraldinsight.com

Sutarjo, (2011). Ten ways of managing person-organization fit (P-O fit effectively): A literature study, International Journal of Business and Social Science, Vol.2 No. 21(Special Issue)

Taris, R., Feij, J.A. \& Vianen, A. E. M. V. (2005). Met expectations and supplies-values fit of Dutch young adults as determinants of work outcomes, International journal of human resource management, Vol. 16, no. 3, p. 366-382

Thomas, T.P. (2013). The effect of Personal Values, Organizational Values, and PersonOrganization Fit on Ethical Behaviors and Organizational Commitment Outcomes among Substance Abuse Counselors: A preliminary Investigation, Lowa Research online, University of Lowa's Institutional Repository, http://ir.uiowa.edu/etd/4920

Verquer, M.L., Beehr, T.A., \& Wagner, S.H. (2003). A meta-analysis of relations between person-organization fit and work attitudes. Journal of Vocational Behavior. Vol.63, p 473-489, (online), www.elsevier.com/locate/jvb.

Vroom, V.H. (1974). "Decision Making and the Leadership Process", Journal of Contemporary Business, Vol. 3, No. 4, 47-64.

Wijesinghe, A.G.K. (2007). Person-organization fit as the strategic tool in organizational management, Mendel Net conference for doctoral students, Burno, Czech Republic. ISBN 978-80-903966-1

Wijesinghe, A.G.K., \& Hurta, J. (2008). Matching People and Organization for Profit, MendelNet PEF, Evropska Scientific Conference posluchacu doktorskeho studia, Provozne ekonomicka faculta, Burno, ISBN: 978-80-87222-03-4. 
DOI: http://doi.org/10.4038/kjm.v6i2.7543

Wijesinghe, A. G. K. (2009). Interactions between Leadership Styles and Person Organization Value Fit on Employee Performance: case by Sri Lanka and Czech Republic, Doctoral thesis summary, ISBN 978-80-7454-162-9 , Tomas Bata University, CZ (on line). 